\title{
Photosynthetic Activity of Six Hop (Humulus lupulus L.) Cultivars under Different Temperature Treatments
}

\author{
Renée L. Eriksen \\ USDA-ARS Forage Seed and Cereal Research Unit, 3450 SW Campus Way, \\ Corvallis, OR 97331
}

\author{
Laban K. Rutto \\ Agricultural Research Station, Virginia State University, Petersburg, VA \\ 23806
}

\section{James E. Dombrowski and John A. Henning USDA-ARS Forage Seed and Cereal Research Unit, 3450 SW Campus Way, Corvallis, OR 97331}

Additional index words. abiotic stress, carbon assimilation, carboxylating efficiency of Rubisco, electrolyte leakage, heat stress

\begin{abstract}
The Pacific Northwest grows the majority of hops in the United States; however, the region is experiencing an increase in the number of days with high heat. In addition, there is an increased interest in growing hops in other warmer regions of the United States. To understand how hop plants respond to high temperatures, we measured several physiological traits of six hop cultivars under a range of temperatures from 15 to $45^{\circ} \mathrm{C}$. We found that hop plants achieved maximal carbon assimilation at temperatures of 21 to $39^{\circ} \mathrm{C}$ when given sufficient water. At temperatures of $41{ }^{\circ} \mathrm{C}$ and higher, all cultivars experienced declines in carbon assimilation. This was likely due to multiple effects on the cell, including damage to photosystem II (PSII), as reflected in declines in $F_{V} / F_{M}$, damage to membrane integrity as reflected in electrolyte leakage at high temperatures, and declines in Rubisco activity likely due to degradation of Rubisco activase, as reflected in declines in $V_{c, \text { max }}$. 'Cascade', 'Willamette', and 'Southern Brewer' may be good candidates for growing in warm climates because all experience relatively high rates of carbon assimilation at high temperatures and did not experience significant declines in $\mathbf{F}_{V} / \mathbf{F}_{M}$ or increases in electrolyte leakage. 'Chinook' appeared susceptible to extreme heat stress and exhibited evidence of irreparable damage to PSII and membrane integrity at $45^{\circ} \mathrm{C}$.
\end{abstract}

The majority of hops in the United States are grown in the Yakima Valley of the Pacific Northwest (PNW), a region that is increasingly experiencing extreme high temperatures. Climate models predict an increase in the frequency of heat waves in Washington state

\footnotetext{
Received for publication 25 Sept. 2019. Accepted for publication 27 Nov. 2019.

Published online 11 March 2020.

We thank Angela Randazzo and M. Shaun Townsend of Oregon State University for advice and help in the field and greenhouse. We thank Christopher J. Still and Gerald Page of Oregon State University for the LI-COR 6400. We thank Claire Phillips of USDA-ARS for the EC meter and Vicky Hollenbeck of USDA-ARS who provided assistance in the laboratory. Ryan Hayes, Neil Adhikari, and three anonymous reviewers provided an invaluable review and comments regarding the manuscript. R.L.E. was supported by the Brewers Association and Washington State Department of Agriculture's Specialty Crop Block Grant Program (K2298).

J.A.H. is the corresponding author. E-mail: john.henning@usda.gov.

This is an open access article distributed under the CC BY-NC-ND license (https://creativecommons.org/ licenses/by-nc-nd/4.0/).
}

in upcoming decades compared with 1970-99, particularly in the south-central hop-growing regions (Salathé et al., 2010). Regional brewers have expressed increasing interest in local sources of hops in other regions of the country as well, including regions that historically have not been considered ideal for hop production because they lack low temperatures for sufficiently long winter dormancy (Bauerle, 2019; Neve, 1991). As the PNW prepares for increasing heat waves, and as production expands in warmer regions of the country, there is a need to understand the response to heat in common cultivars grown in the United States and to describe differences in heat tolerance among cultivars to identify lines for breeding new cultivars with increased abiotic stress tolerance.

Heat principally limits the photosynthetic activity of plants (Berry and Bjorkman, 1980). Allakhverdiev et al. (2008) identified three components of the photosynthetic system that are sensitive to heat damage: the photosystems themselves, particularly photosystem II (PSII); the ATP-generating electron transport chain; and the carbon assimilation process. Heat affects the photosystems by causing the dissociation of manganese $(\mathrm{Mn})$ molecules from the oxygen-evolving complex (OEC) in PSII (Enami et al., 1994, 1998; Nash et al., 1985), by disrupting the distribution of absorbed light energy from the light-harvesting complex to the core of PSII (Pastenes and Horton, 1996), and by disrupting the integrity of the D1 protein (Yoshioka et al., 2006). Heat also disrupts membrane fluidity, leading to the breakdown of the thylakoid membrane integrity, which leads to disruptions in the electron transport chain and ATP synthesis (Gounaris et al., 1983; Inaba and Crandall, 1988). Finally, heat disrupts the Rubisco activase protein (Salvucci and Crafts-Brandner, 2004; Sharkey, 2005), leading to inactivation of the carboxylating enzyme and, ultimately, to cessation of carbon assimilation.

We measured several photosynthetic and physiological traits of six hop cultivars in response to a range of temperatures. 'Cascade', 'Centennial', and 'Chinook' are some of the most commonly grown varieties in the PNW and other regions. 'Willamette' is a triploid variety that our preliminary work has suggested has higher water use efficiency. 'Southern Brewer' is a high alpha variety developed in South Africa for shorter summer days that has been reported to have higher heat tolerance. 'Pride of Ringwood' is a high alpha variety developed in Australia that also may have higher heat tolerance. These findings will provide valuable information for growers developing hop yards in the increasingly warm PNW or in other warmer regions of the United States and for breeding programs aiming to develop cultivars more resilient to high temperatures.

\section{Materials and Methods}

Plant material and experimental conditions. In Feb. 2019, rhizomes were removed from a single plant from the cultivars Cascade, Centennial, Chinook, Pride of Ringwood, Southern Brewer, and Willamette growing at the USDAARS Hop Research fields in Corvallis, OR. The plants were clonally propagated by dividing the rhizomes into six parts and planted in 1-gallon pots with potting soil (Sun Gro Horticulture, Agawam, MA) containing Sphagnum peatmoss, perlite, proprietary nutrient charge, screened pumice, gypsum, dolomite limestone, and proprietary wetting agent; they were allowed to break dormancy in a greenhouse. The plants were maintained there for 4 months and constantly cut back to encourage root growth. Trial 1 plants were moved to Conviron PGR14 growth chambers after 4 months of root growth; trial 2 plants were moved to the growth chambers after 5 months of root growth. Each trial consisted of three plants of each cultivar. Plants were watered regularly and fertilized biweekly with a 24N-8P-16K Miracle-Gro fertilizer (Scotts, Marysville, $\mathrm{OH}$ ) according to the manufacturer's instructions.

Once moved to the growth chambers, the plants were grown under a photoperiod of $14 \mathrm{~h}$ of daylight at $24{ }^{\circ} \mathrm{C}$ and $10 \mathrm{~h}$ of night at $12{ }^{\circ} \mathrm{C}$ to approximate early growth season conditions in the PNW. Irradiance was maximized at $875 \mu \mathrm{mol} \cdot \mathrm{m}^{-2} \cdot \mathrm{s}^{-1}$. We began by measuring physiological traits at $24{ }^{\circ} \mathrm{C}$; temperatures were 
then decreased by $3^{\circ}$ every $24 \mathrm{~h}(21,18$, and $15{ }^{\circ} \mathrm{C}$ ). The plants were allowed to recover for $>24 \mathrm{~h}$ at $24^{\circ} \mathrm{C}$; then, temperatures were increased every $24 \mathrm{~h}\left(27,30,33,36,39,41\right.$, and $\left.45^{\circ} \mathrm{C}\right)$.

Gas exchange and fluorescence measurements. Gas exchange and chlorophyll fluorescence measurements were performed using a LI-6400 Portable Photosynthesis System with a 6400-40 LCF sensor head (LI-COR Biosciences, Lincoln, NE). A single measurement was performed on a mature leaf as well as on a younger leaf at approximately the second or third node below the youngest, fully unfurled leaf because young and mature senescing tissues have different sensitivities to heat stress (Karim et al., 1999; Marias et al., 2017).

Dark-adapted $\mathrm{F}_{\mathrm{o}}$ and $\mathrm{F}_{\mathrm{V}} / \mathrm{F}_{\mathrm{M}}$ measurements were performed after $10 \mathrm{~h}$ of dark adaptation and $3 \mathrm{~h}$ of exposure to the experimental temperature. We optimized the measuring intensity according to the manufacturer's instructions (using the LI-6400/LI-6400XT version 6 manual) at 0.4 and used a flash duration of 0.8 ; all other settings complied with the manufacturer's suggested settings for determining $\mathrm{F}_{\mathrm{V}} / \mathrm{F}_{\mathrm{M}}$.

Gas exchange and light-adapted fluorescence measurements were then performed after $\geq 2 \mathrm{~h}$ of light adaptation and after $>4 \mathrm{~h}$ at the experimental temperature. Gas exchange measurements were performed under saturating photosynthetically active radiation $(P A R)$ of $1000 \mu \mathrm{mol} \cdot \mathrm{m}^{-2} \cdot \mathrm{s}^{-1}$ under atmospheric $\mathrm{CO}_{2}$ concentrations $(400 \mathrm{ppm})$ controlled by a mixer and flow rates of $400 \mu \mathrm{mol} \cdot \mathrm{s}^{-1}$. The block temperature was set to the experimental temperature. The humidity of the reference air was adjusted to ambient levels to the best of our ability to avoid VPD-caused stomatal closure. Measurements were recorded when carbon assimilation and stomatal conductance $\left(g_{\mathrm{S}}\right)$ reached stability, which occurred after $\approx 2 \mathrm{~min}$. Light-adapted fluorescence measurements were performed on the same leaf immediately following gas exchange measurements. We optimized the flash intensity at 8 according to the manufacturer's instructions (using the LI-6400/LI-6400XT version 6 manual); all other LCF settings complied with the manufacturer's suggested settings for determining PSII efficiency ( $\Phi_{\text {PSII }}$ ).

Following survey measurements, a rapid $\mathrm{A} / \mathrm{C}_{i}$ curve was performed at each temperature on one plant of the cultivars Cascade, Centennial, Chinook, and Southern Brewer during trial 1 , and for one plant of the cultivars Cascade, Centennial, Chinook, and Willamette during trial $2 . \mathrm{A} / \mathrm{C}_{i}$ curves could only be created for four plants per day due to time constraints; preliminary measurements indicated carbon assimilation began to decrease in hop plants due to natural circadian patterns $\approx 9 \mathrm{~h}$ after daybreak. The default settings under the autoprogram $\mathrm{ACi} 2$ were used, with $\mathrm{CO}_{2}$ concentrations of 400, 300, 200, 100, 50, 10, 0, 400, $400,500,600,800,1000$, and $1200 \mu \mathrm{mol} \mathrm{CO}_{2}$. Measurements were set to record after standard stability settings, with a minimum wait time of $2 \mathrm{~min}$ and a maximum wait time of $4 \mathrm{~min}$.

Electrolyte leakage and pigment concentrations. In a third trial, we measured the percent electrolyte leakage and pigment concentrations of plants that were grown from softwood cuttings in $10-\mathrm{cm}$ square pots and provided ample water from a bottom tray to mitigate the effects of pot size on soil moisture. At temperatures of $33,36,39,41$, and $45^{\circ} \mathrm{C}$, six $1-\mathrm{cm}$ discs of tissue from six different leaves were excised, capturing both young and mature leaf tissues. The discs were incubated in $20 \mathrm{~mL}$ of de-ionized water in 50-mL tubes at room temperature overnight; the conductivity of the solution was measured after $20 \mathrm{~h}$ using a temperature-compensated EC meter (model 1056; Amber Science, Inc., Eugene, OR). The tubes were then steam-sterilized in an autoclave for $15 \mathrm{~min}$ at $110^{\circ} \mathrm{C}$ to disintegrate the cell materials. After cooling, the total conductivity was measured again, and the electrolyte leakage values were calculated as a percentage of maximum conductivity.

To assess pigment concentrations, two $1-\mathrm{cm}$ discs were excised from a dark green mature leaf and a lighter green younger leaf below the youngest fully unfurled leaf at temperatures of 33, 36, 39, 41, and $45{ }^{\circ} \mathrm{C}$. These discs were placed in a $1.5-\mathrm{mL}$ microcentrifuge tube on ice, kept in a dark box, and soaked in $1 \mathrm{~mL}$ of methanol overnight at $4{ }^{\circ} \mathrm{C}$. The methanol was removed and placed in a $10-\mathrm{mL}$ glass test tube and diluted to $5 \mathrm{~mL}$ methanol to adjust the concentration to the appropriate range for the spectrophotometer. We read absorbance on a Spectronic 20 (Milton Roy Company, Ivyland, PA) at $\approx 470,653$, and $666 \mathrm{~nm}$. The concentrations for chlorophyll $a$ and $b$ and carotenoids were calculated according to Lichtenthaler (1987), with updates for spectrophotometers with a resolution range of 1 to $4 \mathrm{~nm}$ (Wellburn, 1994).

Data analysis. All analyses were performed using $\mathrm{R}$ version 3.4.3. For photosynthetic data, outliers were identified using boxplots and removed from the dataset based on the assumption that they could represent a calibration error introduced by the LI- 6400 . To assess the statistical significance of differences, we performed one-way analyses of variance to test a model of differences within traits among cultivars at each temperature using transformed or untransformed data as appropriate; these tests were followed by pairwise Tukey's honestly significant difference tests, and significance was evaluated against a Bonferroniadjusted alpha value of 0.003 for 15 pairwise comparisons. We used the $\mathrm{R}$ package plant ecophys (Duursma, 2015) to fit $\mathrm{A} / \mathrm{C}_{i}$ curves and calculate parameters using the default nonlinear regression fit method. Temperatures reported are air temperatures because of known biases in leaf temperature measurements (Still et al., 2019).

\section{Results}

For most hop cultivars tested, carbon assimilation (A) was highest between 21 and $39^{\circ} \mathrm{C}$, but some continued to maintain relatively high levels of $\mathrm{A}$ even at $41^{\circ} \mathrm{C}$ (Fig. 1A). Most differences in A among cultivars were not significant at a Bonferroni-adjusted alpha level at any temperature tested here. 'Cascade' maintained high levels of $\mathrm{A}$ between 18 and $39^{\circ} \mathrm{C}$; only the extreme low $\left(15^{\circ} \mathrm{C}\right)$ and extreme high $\left(45^{\circ} \mathrm{C}\right)$ levels tested during this experiment caused reductions in $\mathrm{A}$ in this cultivar. 'Centennial' achieved slightly higher A than 'Cascade' at lower temperatures. 'Willamette' achieved the highest level of $\mathrm{A}$ at the high temperatures of 39 to $41{ }^{\circ} \mathrm{C}$. Carbon assimilation in 'Chinook' was significantly lower at $41{ }^{\circ} \mathrm{C}$ than in 'Willamette' $(P<0.001)$. Most cultivars had low rates of $g_{\mathrm{S}}$ at 15 to $18{ }^{\circ} \mathrm{C}$ despite adequate soil moisture; at $15{ }^{\circ} \mathrm{C}, g_{\mathrm{S}}$ decreased to levels that introduce stomatal limitations to A (Medrano et al., 2002). Rates of $g_{\mathrm{S}}$ reached the maximal level at $27^{\circ} \mathrm{C}$ and then declined with increasing temperatures, although 'Cascade' had significantly higher $g_{\mathrm{S}}$ rates at $36{ }^{\circ} \mathrm{C}\left[\mathrm{F}_{(5,29)}=6.65\right.$; $P<0.001]$ and warmer compared with the other cultivars tested (Fig. 1B). Leaf transpiration (E) was positively correlated with temperature and tended to be higher in 'Cascade' at higher temperatures; E in 'Cascade' was significantly higher than it was in 'Pride of Ringwood' at 36 to $39{ }^{\circ} \mathrm{C}(P<0.003)$ (Fig. 1C). Intercellular $\mathrm{CO}_{2}$ concentrations $\left(\mathrm{C}_{i}\right)$ remained steady between $\approx 250$ and $300 \mathrm{~mol} /$ air at most temperatures, but they were highly variable within cultivars at $15^{\circ} \mathrm{C}$. 'Cascade' and 'Chinook' had higher $\mathrm{C}_{i}$ at the extreme high temperature of $45^{\circ} \mathrm{C}\left[\mathrm{F}_{(5,27)}=3.90 ; P=0.008\right]$ (Fig. 1D).

Traits that reflect the health of the lightharvesting system (PSII efficiency or $\Phi_{\text {PSII }}$ and ETR) for the different cultivars displayed trends similar to those observed in A. However, these traits reached peak rates at temperatures between 27 and $31{ }^{\circ} \mathrm{C}$ (Fig. 1E and $\mathrm{G}$ ), which was slightly warmer than the temperatures at which we observed peak rates of A. 'Willamette' had slightly higher $\Phi_{\text {PSII }}$ and ETR at $41{ }^{\circ} \mathrm{C}\left[\mathrm{F}_{(5,28)}=3.65 ; P=0.01\right]$. Nonphotochemical quenching (NPQ), as a measure of stress to the photosynthetic apparatus, was highly variable at $15{ }^{\circ} \mathrm{C}$; then, it remained steady between 24 and $39{ }^{\circ} \mathrm{C}$ and increased sharply at 41 and $45^{\circ} \mathrm{C}$ (Fig. $\left.1 \mathrm{H}\right) . \mathrm{F}_{\mathrm{o}}$ is the initial dark-adapted chlorophyll fluorescence level with $\mathrm{Q}_{\mathrm{A}}$ fully oxidized and "open." This measure decreased from 15 to $27{ }^{\circ} \mathrm{C}$; then, it continued to increase from 33 to $41^{\circ} \mathrm{C}$. In 'Chinook', it increased significantly at $45^{\circ} \mathrm{C}$ (Fig. 2A). The measure of photoinhibition $\mathrm{F}_{\mathrm{V}} / \mathrm{F}_{\mathrm{M}}$ remained at nonstress levels $(\approx 0.8)$ for temperatures 15 to $33{ }^{\circ} \mathrm{C}$. At $36{ }^{\circ} \mathrm{C}$, 'Chinook' and 'Southern Brewer' began to show early signs of damage. However, 'Chinook' was the only cultivar to experience significantly lower $\mathrm{F}_{\mathrm{V}} / \mathrm{F}_{\mathrm{M}}$ ratios at $41^{\circ} \mathrm{C}\left[\mathrm{F}_{(5,30)}=8.96 ; P<0.001\right)$ and $45^{\circ} \mathrm{C}\left[\mathrm{F}_{(5,30)}=4.09 ; P=0.006\right]$ (Fig. 2B).

The maximum carboxylating efficiency of Rubisco $\left(\mathrm{V}_{c, \text { max }}\right)$ was positively correlated with temperature until $39^{\circ} \mathrm{C}\left(R^{2}=0.83 ; P<0.001\right)$; at temperatures warmer than $39{ }^{\circ} \mathrm{C}, \mathrm{V}_{c, \max }$ decreased in all cultivars (Fig. 3). $\mathrm{V}_{c, \max }$ was similar among cultivars at temperatures of 15 to $30{ }^{\circ} \mathrm{C}$. Although more replication is necessary, the $\mathrm{V}_{c, \max }$ appeared to increase more overall in 'Southern Brewer' compared with the other cultivars at temperatures $>30{ }^{\circ} \mathrm{C}$. 'Chinook' displayed the lowest $\mathrm{V}_{c, \max }$ value at $45^{\circ} \mathrm{C}$.

The percentage of electrolytes leaked from cell tissue was relatively steady for all 

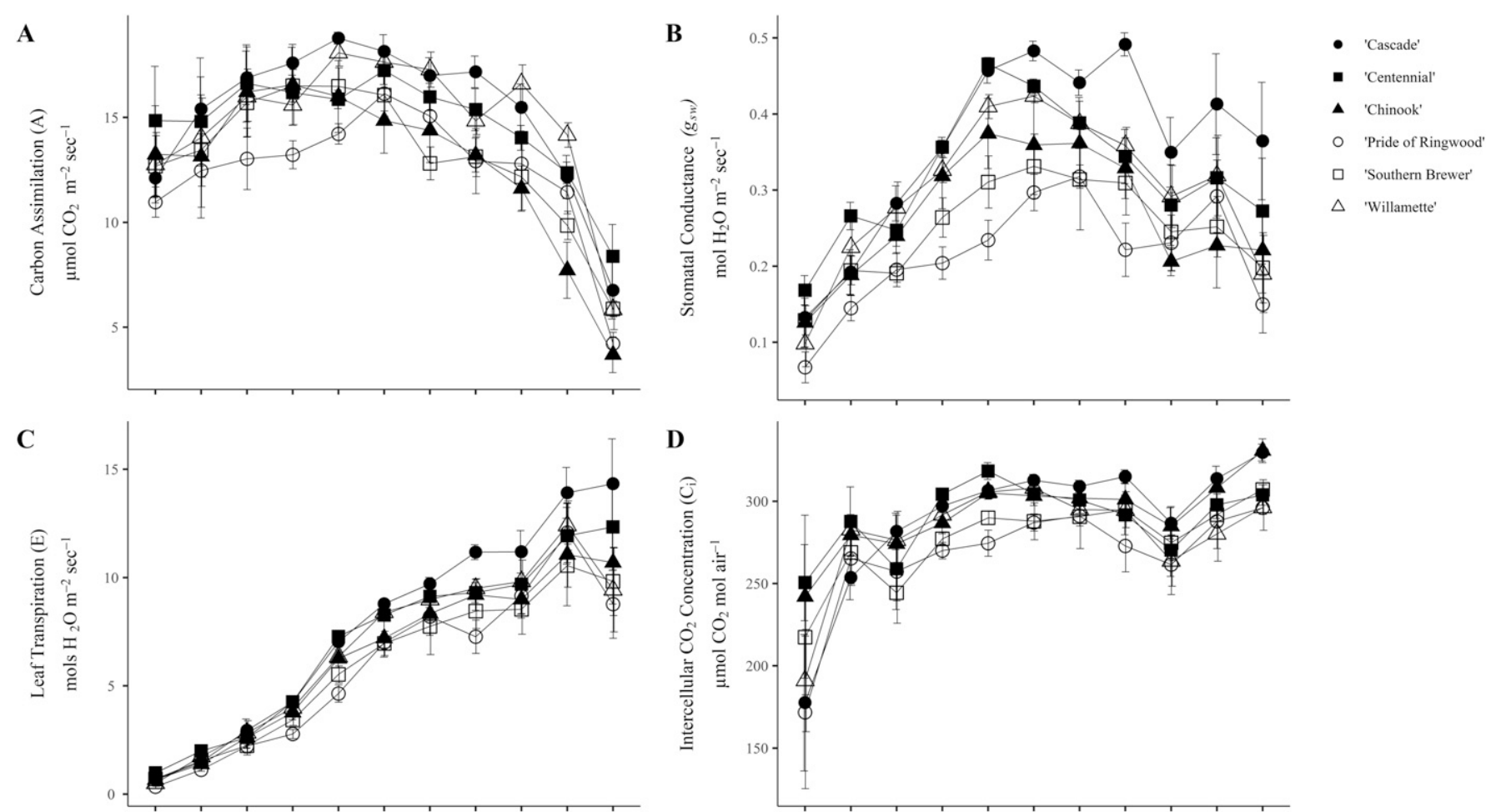

$\mathbf{E}$
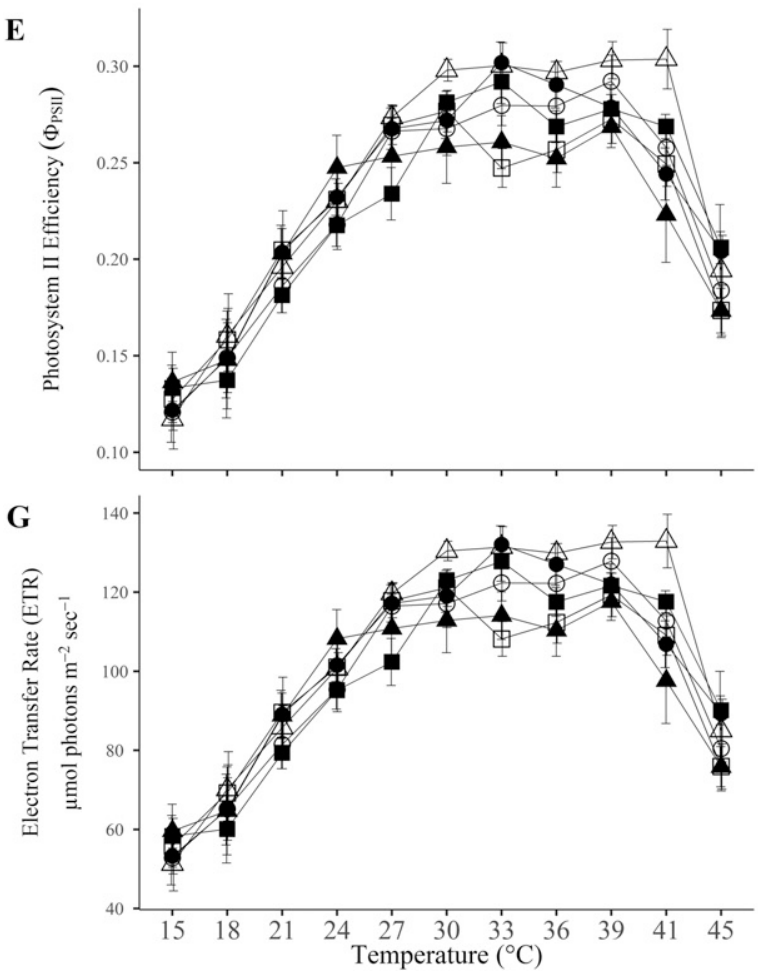

F
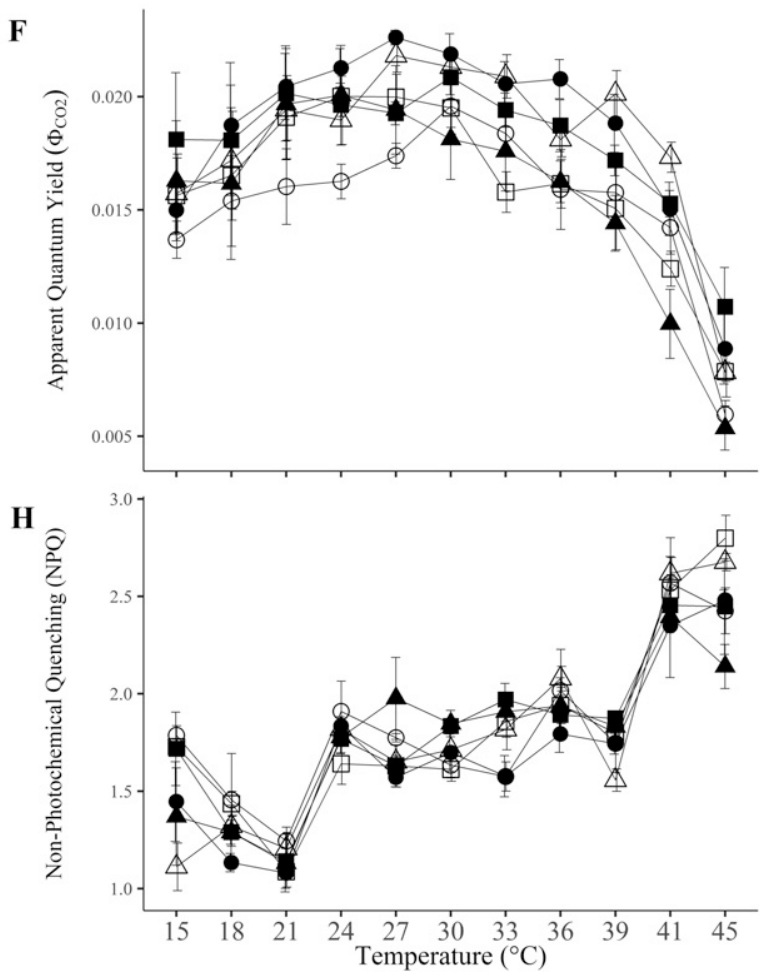

Fig. 1. Photosynthetic traits measured at $1000 \mu \mathrm{mol}$ photons $/ \mathrm{m}^{2} / \mathrm{s}$ for each cultivar. Error bars represent the sEm value for six plants. (A) Carbon assimilation (A). (B) Stomatal conductance $\left(g_{\mathrm{S}}\right)$. (C) Leaf transpiration (E). (D) Intercellular carbon concentration $\left(\mathrm{C}_{i}\right)$. (E) Photosystem II efficiency $\left(\Phi_{\mathrm{PSII}}\right)$. (F) Apparent quantum yield $\left(\Phi_{\mathrm{CO} 2}\right)$. (G) Electron transfer rate $(\mathrm{ETR})$. (H) Nonphotochemical quenching $(\mathrm{NPQ})$.

the cultivars at temperatures between 33 and $39{ }^{\circ} \mathrm{C}$, but they increased sharply in 'Pride of Ringwood', 'Chinook', and 'Centennial' at $45{ }^{\circ} \mathrm{C}\left[\mathrm{F}_{(5,18)}=19.61 ; P<0.001\right)$. However, 'Cascade', 'Southern Brewer', and 'Willamette' displayed only slight increases at $45{ }^{\circ} \mathrm{C}$ (Fig. 4). It should be noted that all cultivars showed visible damage to leaf tissue in the form of leaf curling and cell death at leaf edges at this temperature.
Changes to pigment ratios can indicate damage to the light-harvesting complexes. There were no significant changes in the ratio of chlorophyll $a$ to chlorophyll $b$ at the temperatures tested (Fig. 5A), and the concentration of carotenoids within cultivars also remained relatively steady over the temperatures tested here (Fig. 5B). Only 'Willamette' and 'Pride of Ringwood' had significantly higher antioxidant carotenoid concentrations at $41{ }^{\circ} \mathrm{C}\left[\mathrm{F}_{(5,42)}=11.94\right.$; $P<0.001]$, and these concentrations decreased at $45^{\circ} \mathrm{C}$.

\section{Discussion}

The major hop-growing regions of the United States are experiencing an increase in the number of days with extreme high temperatures. At the same time, there is increased 

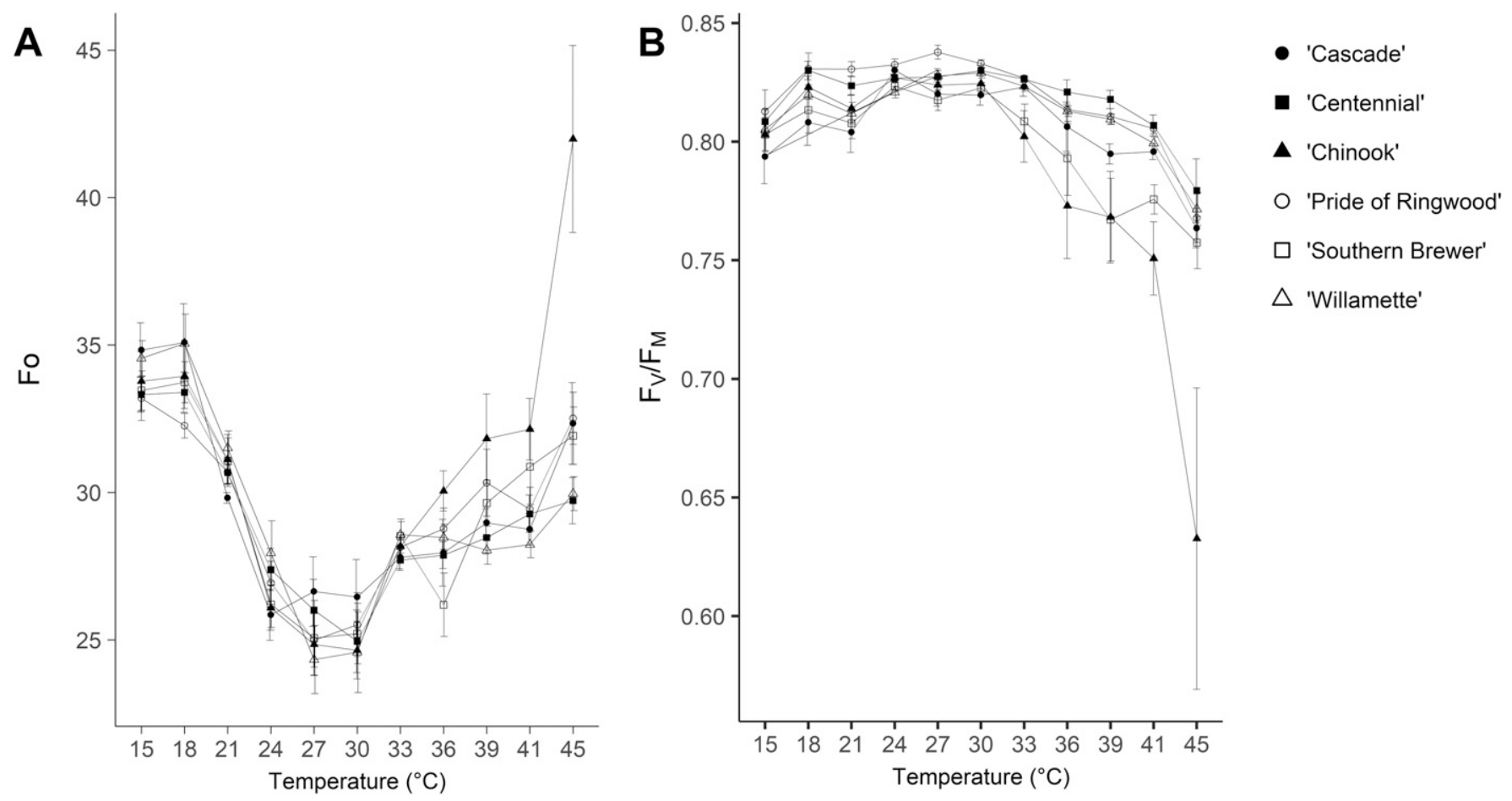

Fig. 2. Dark-adapted chlorophyll fluorescence measurements for each cultivar. Error bars represent the sEM value for six plants. (A) $F_{\mathrm{o}}$. (B) $F_{V} / F_{M}$.

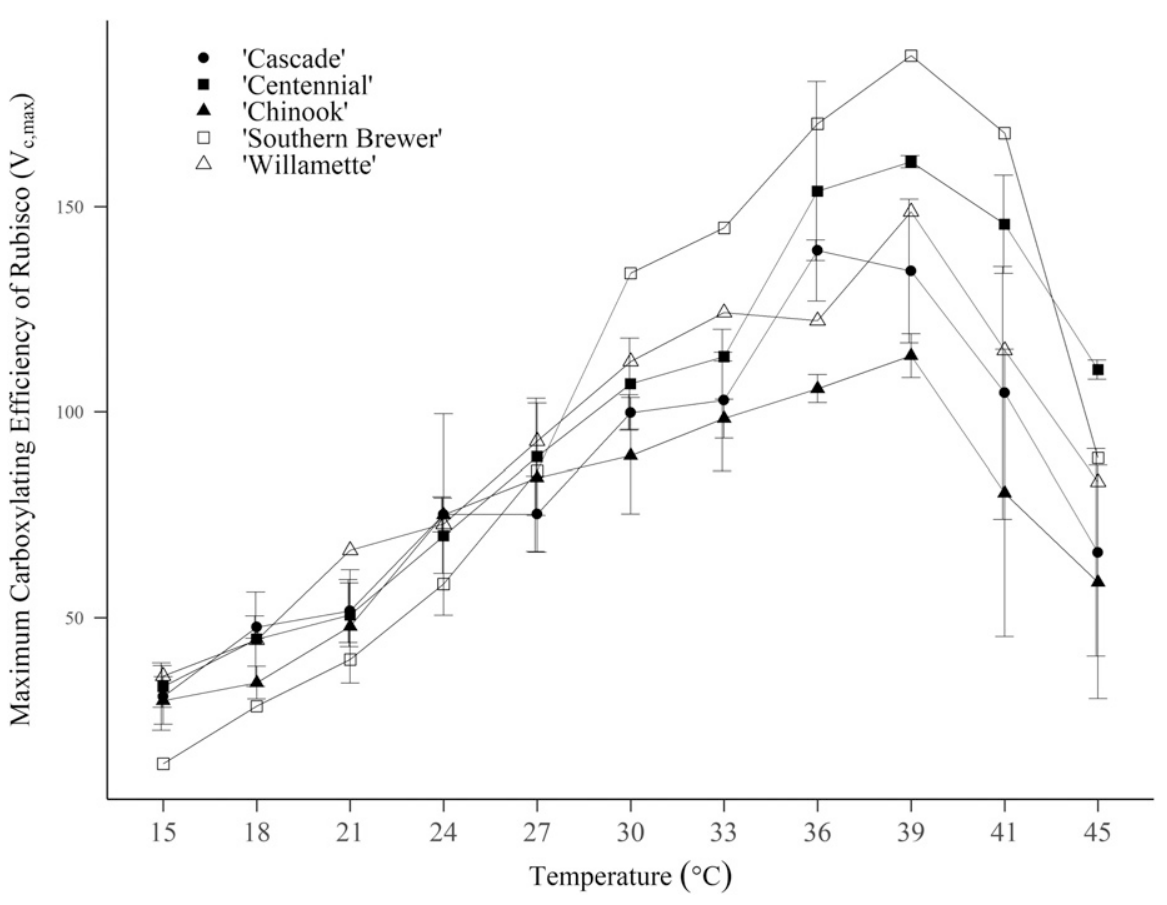

Fig. 3. The maximum carboxylating efficiency $\left(\mathrm{V}_{c, \max }\right)$ of Rubisco for each cultivar. Error bars, when present, represent the SEM.

interest among growers in expanding production to different parts of the country. A more pressing issue for growth in other regions of the United States will be an appropriate photoperiod for cone production (Bauerle, 2019; Neve, 1991); however, high temperatures during the growing season are also a valid concern. Most plants appear to have an optimum temperature for photosynthesis and can acclimate to different temperature ranges (Berry and Bjorkman, 1980). However, some plants are better adapted to higher temperatures than others and are better able to acclimate to higher photosynthesis and higher productivity. We tested six hop cultivars to observe differences in their photosynthetic responses to increasing high temperatures. Our goals were as follows: 1) to identify the grown hop cultivars photosynthesize, 2) to describe differences among cultivars in their tolerance to heat to identify cultivars that might range of temperatures at which commonly be better suited for growth in warmer regions of the United States, and to identify cultivars for use in breeding programs to increase resilience to abiotic stress.

Carbon assimilation and $\Phi_{\mathrm{CO} 2}$ reached maximum rates between 21 and $39^{\circ} \mathrm{C}$, whereas $\Phi_{\text {PSII }}$ and ETR in these hop cultivars all reached maximum rates at slightly warmer temperatures between 27 and $39^{\circ} \mathrm{C}$ (Fig. 1). This range is slightly warmer than the range considered optimum for most $\mathrm{C}_{3}$ photosynthetic plants at 20 to $35{ }^{\circ} \mathrm{C}$ (Sage et al., 2008); however, the shape of the temperature response curve was typical of most $\mathrm{C} 3$ plants.

Indicators of stress on the photosynthetic system, NPQ (Fig. 1H), and $\mathrm{F}_{\mathrm{V}} / \mathrm{F}_{\mathrm{M}}$ (Fig. 2B) also indicated that this range of temperatures from 24 to $39{ }^{\circ} \mathrm{C}$ was optimum for growth, although there were some early indications of photoinhibition in 'Chinook' and 'Southern Brewer' at $39^{\circ} \mathrm{C}$ (Fig. 2B). $\mathrm{F}_{\mathrm{o}}$ increases sharply under heat treatments, and this is attributed to the irreversible dissociation of the lightharvesting complex, the reversible inactivation of PSII, and the reduction of QA by plastoquinone from the PSII reaction center (Yamane et al., 1997, 1998, 2000); in these experiments, $\mathrm{F}_{\mathrm{o}}$ increased sharply in 'Chinook' at $45^{\circ} \mathrm{C}$.

Broadly speaking, this range of 21 to $39^{\circ} \mathrm{C}$ appeared to be the range of optimal growth for the hop cultivars tested in this study, and the range of 27 to $39{ }^{\circ} \mathrm{C}$ produced maximal values for both $\Phi_{\mathrm{PSII}}$ and $\Phi_{\mathrm{CO} 2}$. There was little statistically significant variation among cultivars; however, 'Pride of Ringwood' appeared to not reach maximum levels of A until $30{ }^{\circ} \mathrm{C}$ and 'Willamette' remained near maximal levels at $41{ }^{\circ} \mathrm{C}$ when other cultivars appeared to suffer reductions in A due to heat (Fig. 1A). 


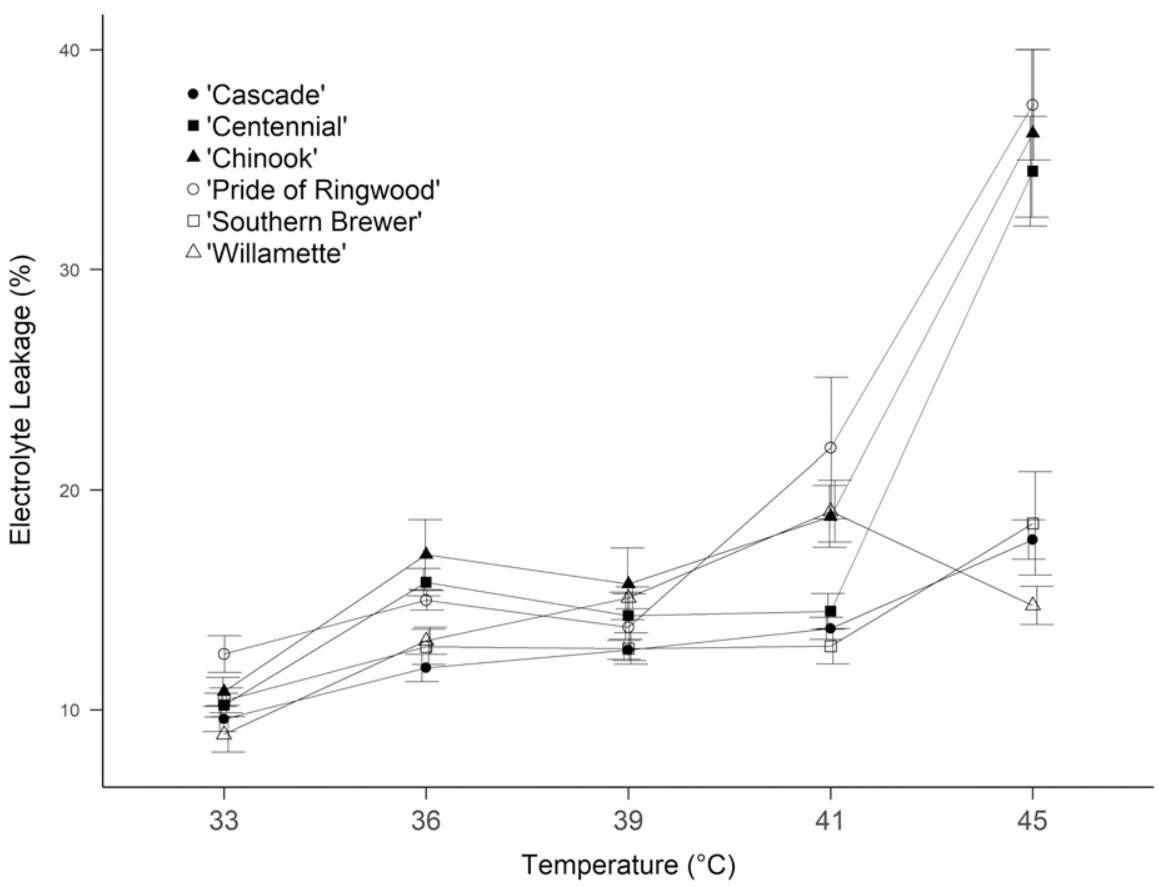

Fig. 4. Percent electrolyte leakage at different temperatures. Error bars represent the sEM value for four plants.

'Pride of Ringwood' generally did not thrive under these experimental conditions, and plants remained small throughout the experiment. A different photoperiod may produce different results in 'Pride of Ringwood', but the photoperiod tested was chosen to represent earlyseason conditions in the PNW when rapid bine growth occurs.

'Cascade' had high levels of A over a range of temperatures 24 to $39^{\circ} \mathrm{C}$ (Fig. 1A); therefore, it appears to be a strong candidate for growing in the increasingly warm PNW, for growing in other warm areas of the country, and for breeding programs for increased abiotic stress tolerance. 'Willamette' had higher A, $\Phi_{\mathrm{PSI}}, \Phi_{\mathrm{CO} 2}$, and ETR than 'Cascade' at $41^{\circ} \mathrm{C}$ (Fig. 1). In regions where temperatures are likely to reach $>40{ }^{\circ} \mathrm{C}$, 'Willamette' may also have strong growth potential if the photoperiod is appropriate for cone production. 'Chinook' appears to be a poor candidate for warmer climates because it had some of the lowest A rates at temperatures of 39 to $45^{\circ} \mathrm{C}$ (Fig. 1A) and exhibited signs of irreparable damage to the photosystems and cell membranes at the extreme high temperature of $45^{\circ} \mathrm{C}$, as seen by the rapid increase in $\mathrm{F}_{o}$ (Fig. 2A) and electrolyte leakage (Fig. 3) and the rapid decrease in $F_{V} / F_{M}$ (Fig. 2B).

The positive correlation of $\mathrm{E}$ and temperature (Fig. 1C) suggested that high A was, in part, a result of the cooling effect of evapotranspiration; therefore, a reliable water source to supply that evapotranspiration at high temperatures is necessary. This study did not examine the often-concomitant stresses of heat and drought. However, almost all hop production fields in the PNW are irrigated, and drought is more easily alleviated than high temperatures. $g_{\mathrm{S}}$ reached peak rates at $27^{\circ} \mathrm{C}$; then, it decreased in most cultivars except 'Cascade', which remained high throughout increases in $F_{o}$ and significant decreases in $\mathrm{F}_{\mathrm{V}} / \mathrm{F}_{\mathrm{M}}$. Under these experimental conditions, PSII in hops appeared relatively robust in temperatures of 15 to $41^{\circ} \mathrm{C}$. There was early evidence of a decrease in $F_{V} / F_{M}$ in 'Southern Brewer' and 'Chinook' at $36{ }^{\circ} \mathrm{C}$, and all cultivars began to experience some decreases in $\mathrm{F}_{\mathrm{V}} / \mathrm{F}_{\mathrm{M}}$ at $45^{\circ} \mathrm{C}$. However, these experimental conditions only produced a sharp rise in $\mathrm{F}_{\mathrm{o}}$ and significant decreases in $\mathrm{F}_{\mathrm{V}} / \mathrm{F}_{\mathrm{M}}$, suggesting severe and irreparable damage to PSII in one cultivar at $45^{\circ} \mathrm{C}$. Damage to PSII due to heat stress produces reactive oxygen species in the plant, leading to increases in lipophilic antioxidants such as carotenoids (Das and Roychoudhury, 2014; Suzuki and Mittler, 2006), which have been shown to stabilize the thylakoid membrane by decreasing membrane fluidity (Havaux, 1993). Under temperatures 33 to $45^{\circ} \mathrm{C}$, an increase in carotenoids was only seen in 'Pride of Ringwood' and 'Willamette' at $41{ }^{\circ} \mathrm{C}$. The levels of antioxidant carotenoids remained relatively steady among samples of the same cultivar but were lowest in 'Chinook' samples (Fig. 5). The lack of increases in carotenoids within cultivars could be because carotenoid concentrations were already high at $33{ }^{\circ} \mathrm{C}$ when samples were first obtained. Increases in carotenoid concentrations in 'Willamette' may partially explain this cultivar's resilience to heat stress; however, similar increases in the less resilient 'Pride of Ringwood' suggest that carotenoids are not the primary factor influencing heat resilience.

Heat stress causes structural changes in the thylakoid membranes, which are reflected in ion leakage (Inaba and Crandall, 1988; Wahid and Shabbir, 2005; Yang et al., 1996). Evidence of breakdown of the thylakoid membranes indicated by a rapid increase in electrolyte leakage was seen in 'Chinook', 'Centennial', and 'Pride of Ringwood' (Fig. 4). 'Cascade', 'Southern Brewer', and 'Willamette' appear to maintain membrane integrity even at $45^{\circ} \mathrm{C}$; 'Willamette' appears to possibly recover membrane integrity and experiences a reduction in electrolyte leakage at $45^{\circ} \mathrm{C}$ compared with $41{ }^{\circ} \mathrm{C}$, which should be investigated further. In Chlamydomonas, saturation of membrane lipids acts to stabilize the membranes and PSII under heat stress (Sato et al., 1996). As a triploid cultivar, Willamette may have higher expression of proteins that adjust the lipid composition to increase membrane resiliency; however, from these data, it is not possible to determine the exact mechanism of increased resilience or whether the increased resilience is common among triploids.

The carboxylating enzyme Rubisco exhibits affinities for both $\mathrm{CO}_{2}$ and $\mathrm{O}_{2}$, despite the waste of resources involved in fixing $\mathrm{O}_{2}$ (i.e., photorespiration). Under increasing temperatures, the solubility of $\mathrm{CO}_{2}$ decreases, thus decreasing $\mathrm{CO}_{2}$ movement through the aqueous portions of the plant cell, thereby decreasing the availability of $\mathrm{CO}_{2}$ at the sites of carboxylation. At the same time, the affinity of Rubisco for $\mathrm{CO}_{2}$ decreases at high temperatures, causing an increase in $\mathrm{O}_{2}$ fixation and photorespiration (Slattery and Ort, 2019). In addition, the activation state of Rubisco 

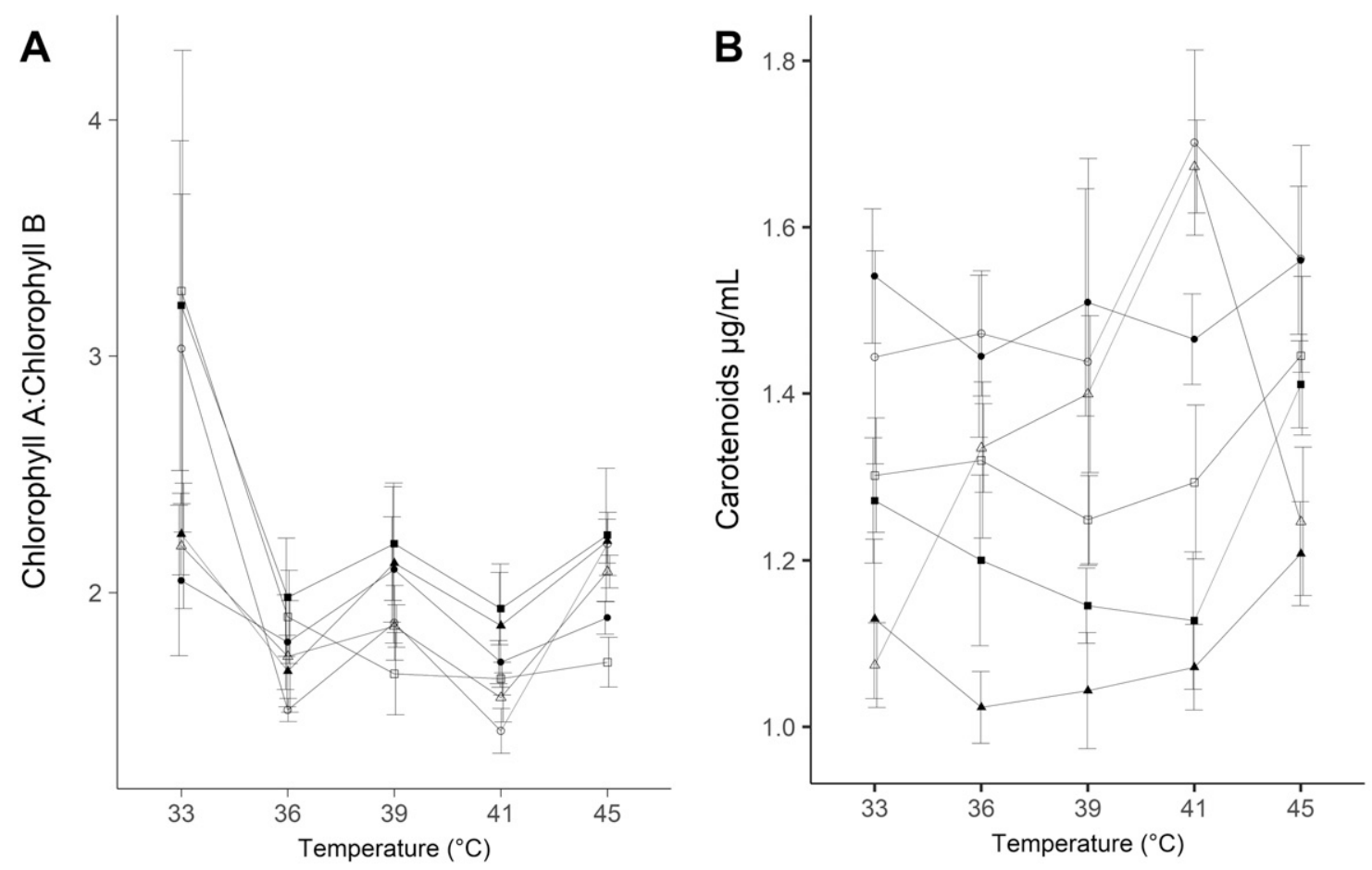

- 'Cascade'

- 'Centennial'

A 'Chinook'

○ 'Pride of Ringwood'

'Southern Brewer'

$\triangle$ 'Willamette'

Fig. 5. The ratio of chlorophyll $a$ to chlorophyll $b$ at different temperatures (A) and the concentration of total carotenoids at different temperatures (B). Error bars represent the SEM value for four plants.

decrease above a species-specific optimum temperature (Sage et al., 2008). In hops, this transition to decreased activation of Rubisco appears to occur at temperatures $>39^{\circ} \mathrm{C}$, at which $\mathrm{V}_{c, \max }$ appears to decrease. Although the replication was low, the $\mathrm{V}_{c, \text { max }}$ in 'Southern Brewer' remained high at $41^{\circ} \mathrm{C}$. Rubisco itself is known to be stable at temperatures up to $50{ }^{\circ} \mathrm{C}$ (Crafts-Brandner and Salvucci, 2000); therefore, the decline in Rubisco activity at high temperatures seen in all plants is attributed to declines in Rubisco activase activity (Hikosaka et al., 2006; Salvucci and CraftsBrandner, 2004; Sharkey, 2005; Yamori et al., 2014), which can no longer efficiently remove metabolites from the catalytic sites of Rubisco above certain temperatures and eventually denatures (Feller et al., 1998; Salvucci et al., 2001). Sage et al. (2008) showed that Rubisco activase activity was limiting at temperatures $>30{ }^{\circ} \mathrm{C}$ in the boreal species black spruce (Picea mariana), and that adaptation to hightemperature environments across the range of red maple (Acer rubrum) is due to an increased ratio of Rubisco activase to Rubisco (Weston et al., 2007). Differences in $\mathrm{V}_{c \text {, max }}$ among cultivars at high temperatures may represent different ratios of Rubisco activase to Rubisco or different tolerances of Rubisco activase to heat stress that should be investigated further.

\section{Conclusions}

Hops achieved maximal carbon assimilation at temperatures of 21 to $39^{\circ} \mathrm{C}$ when given sufficient water. 'Cascade' and 'Willamette' experienced relatively high rates of A at high temperatures, whereas 'Southern Brewer' appeared to have higher carboxylating efficiency at high temperatures. 'Cascade', 'Willamette', and 'Southern Brewer' did not experience sharp increase in $\mathrm{F}_{\mathrm{o}}$, significant decrease in $\mathrm{F}_{\mathrm{V}} / \mathrm{F}_{\mathrm{M}}$, or increases in electrolyte leakage. These cultivars may be good candidates for growth in warm climates. 'Cascade' and 'Southern Brewer' may be good candidates for use as breeding lines to improve abiotic stress tolerance. 'Chinook' appears particularly susceptible to extreme heat stress, exhibiting evidence of irreparable damage to PSII and membrane integrity at the highest temperatures tested in this study.

\section{Literature Cited}

Allakhverdiev, S.I., V.D. Kreslavski, V.V. Klimov, D.A. Los, R. Carpentier, and P. Mohanty. 2008. Heat stress: An overview of molecular responses in photosynthesis. Photosynth. Res. 98:541-550.

Bauerle, W.L. 2019. Disentangling photoperiod from hop vernalization and dormancy for global production and speed breeding. Sci. Rep. 9:16003, doi: 10.1038/s41598-019-52548-0.

Berry, J. and O. Bjorkman. 1980. Photosynthetic response and adaptation to temperature in higher plants. Annu. Rev. Plant Physiol. 31:491-543.

Crafts-Brandner, S.J. and M.E. Salvucci. 2000. Rubisco activase constrains the photosynthetic potential of leaves at high temperature and $\mathrm{CO} 2$. Proc. Natl. Acad. Sci. USA 97:13430-13435.

Das, K. and A. Roychoudhury. 2014. Reactive oxygen species (ROS) and response of antioxidants as ROS-scavengers during environmental stress in plants. Front. Environ. Sci. 2:1-13, doi: $10.3389 /$ fenvs. 2014.00053

Duursma, R.A. 2015. Plantecophys - An R package for analysing and modelling leaf gas exchange data. PLoS One 10, doi: 10.1371/journal.pone.0143346. Enami, I., M. Kamo, H. Ohta, S. Takahashi, T. Miura, M. Kusayanagi, S. Tanabe, A. Kamei, A. Motoki,
M. Hirano, T. Tomo, and K. Satoh. 1998. Intramolecular cross-linking of the extrinsic $33-\mathrm{kDa}$ protein leads to loss of oxygen evolution but not its ability of binding to photosystem II and stabilization of the manganese cluster. J. Biol. Chem. 20:4629-4634.

Enami, I., M. Kitamura, T. Tomo, Y. Isokawa, H. Ohta, and S. Katoh. 1994. Is the primary cause of thermal inactivation of oxygen evolution in spinach PS II membranes release of the extrinsic $33 \mathrm{kDa}$ protein or of Mn? BBA - Bioenerg. 1186:52-58.

Feller, U., S.J. Crafts-Brandner, and M.E. Salvucci. 1998. Moderately high temperatures inhibit ribulose-1,5-bisphosphate carboxylase/ oxygenase (Rubisco) activase-mediated activation of Rubisco 1. 116:539-546.

Gounaris, K., A.P.R. Brain, P.J. Quinn, and W.P. Williams. 1983. Structural and functional changes associated with heat-induced phaseseparations of non-bilayer lipids in chloroplast thylakoid membranes. FEBS Lett. 153:47-52.

Havaux, M. 1993. Rapid photosynthetic adaptation to heat stress triggered in potato leaves by moderately elevated temperatures. Plant Cell Environ. 16:461-467.

Hikosaka, K., K. Ishikawa, A. Borjigidai, O. Muller, and Y. Onoda. 2006. Temperature acclimation of photosynthesis: Mechanisms involved in the changes in temperature dependence of photosynthetic rate. J. Expt. Bot. 57:291-302.

Inaba, M. and P.G. Crandall. 1988. Electrolyte leakage as an indicator of high-temperature injury to harvested mature green tomatoes. J. Amer. Soc. Hort. Sci. 113:96-99.

Karim, M.A., Y. Fracheboud, and P. Stamp. 1999. Photosynthetic activity of developing leaves of Zea mays is less affected by heat stress than that of developed leaves. Physiol. Plant. 105:685693.

Lichtenthaler, H.K. 1987. Chlorophylls and carotenoids: Pigments of photosynthetic Biomembranes, p. 350-382. In: L. Packer and R. Douce (eds.). Methods Enzymol. Academic Press. 
Marias, D.E., F.C. Meinzer, and C. Still. 2017. Impacts of leaf age and heat stress duration on photosynthetic gas exchange and foliar nonstructural carbohydrates in Coffea arabica. Ecol. Evol. 7:1297-1310.

Medrano, H., J.M. Escalona, J. Bota, J. Gulías, and J. Flexas. 2002. Regulation of photosynthesis of C3 plants in response to progressive drought: Stomatal conductance as a reference parameter. Ann. Bot. 89:895-905.

Nash, D., M. Miyao, and N. Murata. 1985. Heat inactivation of oxygen evolution in Photosystem II particles and its acceleration by chloride depletion and exogenous manganese. BBA - Bioenerg. 807:127-133.

Neve, R.A. 1991. Hops. 1st ed. Chapman and Hall, Bury St. Edmunds.

Pastenes, C. and P. Horton. 1996. Effect of high temperature on photosynthesis in beans (II. CO2 assimilation and metabolite contents). Plant Physiol. 112:1253-1260.

Pons, T.L. and R.A.M. Welschen. 2003. Midday depression of net photosynthesis in the tropical rainforest tree Eperua grandiflora: Contributions of stomatal and internal conductances, respiration and Rubisco functioning. Tree Physiol. 23:937-947.

Sage, R.F., D.A. Way, and D.S. Kubien. 2008. Rubisco, Rubisco activase, and global climate change. J. Exp. Bot. 59:1581-1595.

Salathé, E.P., L.R. Leung, Y. Qian, and Y. Zhang. 2010. Regional climate model projections for the State of Washington. Clim. Change 102:51-75.

Salvucci, M.E. and S.J. Crafts-Brandner. 2004. Relationship between the heat tolerance of photosynthesis and the thermal stability of Rubisco activase in plants from contrasting thermal environments. Plant Physiol. 134:1460-1470.
Salvucci, M.E., K.W. Osteryoung, S.J. CraftsBrandner, and E. Vierling. 2001. Exceptional sensitivity of Rubisco activase to thermal denaturation in vitro and in vivo. Plant Physiol. 127:1053-1064.

Sato, N., K. Sonoike, A. Kawaguchi, and M. Tsuzuki. 1996. Contribution of lowered unsaturation levels of chloroplast lipids to high temperature tolerance of photosynthesis in Chlamydomonas reinhardtii. J. Photochem. Photobiol. Bol. Biol. 36:333-337.

Sharkey, T.D. 2005. Effects of moderate heat stress on photosynthesis: Importance of thylakoid reactions, rubisco deactivation, reactive oxygen species, and thermotolerance provided by isoprene. Plant Cell Environ. 28:269-277.

Slattery, R.A. and D.R. Ort. 2019. Carbon assimilation in crops at high temperatures. Plant Cell Environ. 42:2750-2758.

Still, C.J., A. Sibley, G. Page, F.C. Meinzer, and S. Sevanto. 2019. When a cuvette is not a canopy: A caution about measuring leaf temperature during gas exchange measurements. Agr. For. Meteorol. 279:107737.

Suzuki, N. and R. Mittler. 2006. Reactive oxygen species and temperature stresses: A delicate balance between signaling and destruction. Physiol. Plant. 126:45-51.

Wahid, A. and A. Shabbir. 2005. Induction of heat stress tolerance in barley seedlings by pre-sowing seed treatment with glycinebetaine. Plant Growth Regulat. 46:133-141.

Wellburn, A.R. 1994. The spectral determination of chlorophylls a and b, as well as total carotenoids, using various solvents with spectrophotometers of different resolution. J. Plant Physiol. 144:307-313.

Weston, D.J., W.L. Bauerle, G.A. Swire-Clark, B.D. Moore, and W.M.V. Baird. 2007. Char- acterization of rubisco activase from thermally contrasting genotypes of Acer rubrum (Aceraceae). Amer. J. Bot. 94:926-934.

Yamane, Y., Y. Kashino, H. Koike, and K. Satoh. 1997. Increases in the fluorescence $F(o)$ level and reversible inhibition of photosystem II reaction center by high-temperature treatments in higher plants. Photosynth. Res. 52:57-64.

Yamane, Y., Y. Kashino, H. Koike, and K. Satoh. 1998. Effects of high temperatures on the photosynthetic systems in spinach: Oxygenevolving activities, fluorescence characteristics and the denaturation process. Photosynth. Res. 57:51-59.

Yamane, Y., T. Shikanai, Y. Kashino, H. Koike, and K. Satoh. 2000. Reduction of $Q(A)$ in the dark: Another cause of fluorescence $F(o)$ increases by high temperatures in higher plants. Photosynth. Res. 63:23-34.

Yamori, W., K. Hikosaka, and D.A. Way. 2014. Temperature response of photosynthesis in C3, $\mathrm{C} 4$, and CAM plants: Temperature acclimation and temperature adaptation. Photosynth. Res. 119:101-117.

Yang, G., D. Rhodes, and R.J. Joly. 1996. Effects of high temperature on membrane stability and chlorophyll fluorescence in glycinebetainedeficient and glycinebetaine- containing maize lines. Aust. J. Plant Physiol. 23:437-443.

Yoshioka, M., S. Uchida, H. Mori, K. Komayama, S. Ohira, N. Morita, T. Nakanishi, and Y. Yamamoto. 2006. Quality control of photosystem II: Cleavage of reaction center D1 protein in spinach thylakoids by $\mathrm{FtsH}$ protease under moderate heat stress. J. Biol. Chem. 281:21660-21669. 